\title{
Ceno
}

8

PERIÓDICO DO PROGRAMA DE PÓS-GRADUAÇÃO EM ARTES CÊNICAS

INSTITUTO DE ARTES | DEPARTAMENTO DE ARTE DRAMÁTICA UNIVERSIDADE FEDERAL DO RIO GRANDE DO SUL

\section{FRAGMENTOS DE UM TEATRO AMOROSO}

\author{
João Pedro Alcantara Gil ${ }^{1}$ \\ (Desenhos de Rodrigo Núñez²)
}

\footnotetext{
${ }^{1}$ Mestre e doutor em educação. Professor de teatro.

${ }^{2}$ Professor de Artes Visuais - UFRGS
} 
RESUMO: O trabalho apresenta como temática o teatro em suas múltiplas linguagens, observado através do olhar afetuoso do autor em seus mais de 30 anos de carreiras artística e docente. Trata-se de uma reunião de artigos jornalísticos revistos, ampliados e ilustrados. $\mathrm{O}$ autor convida os leitores a discutirem o fazer teatral contemporâneo, com base nas suas experiências de encenador e espectador, na expectativa de promover um amadurecimento crítico dos sujeitos envolvidos nos processos artísticos e pedagógicos com teatro.

PALAVRAS-CHAVE: Teatro; Educação; Crítica.

ABSTRACT: This work presents as main topic the art of theatre in its multiple languages, observed through the passionate point of view of the author from his over 30-years career as an artist and teacher. Through a compilation of reviewed, amplified and illustrated journalistic articles, the author invites the readers to discuss the contemporary theatre practice based on his experiences as stage director and spectator, with the prospect of promoting a critical improvement of individuals involved in creative and educational processes related to the drama field.

KEYWORDS: Theatre; Education; Critic.

1. "A minha vida já é um teatro" era a desculpa mais ouvida de quem não queria assistir a teatro naqueles tempos de Santa Maria ${ }^{3}$. Quem iria imaginar que o teatro nestes tempos de Porto Alegre ${ }^{4}$ iria se constituir, em muitos casos, das histórias de vida dos atores, com direito ao nome próprio, endereço e CPF? O espetáculo "Clube do Fracasso", estreado em 2010 e dirigido por Patricia Fagundes, é um bom exemplo de narrativas pessoais para demonstrar as fraquezas do ser humano. O fenômeno teatral foi se transformando ao longo do tempo. As artes cênicas, que tinham funções específicas de divertir, reflexionar uma realidade e produzir um conhecimento específico, foram, para além do jogo, encontrar autobiografias para reafirmar seu sentido de busca da verdade. Mas onde está a verdade? Heidegger (2009) vai dizer que a essência da verdade é a liberdade e esta compreensão do ser, da totalidade, da síntese do universo físico, só é possível com uma disponibilidade para o conhecimento, pela verdade do ser. O conhecimento em teatro não é apenas um saber acumulado pela humanidade, na qual são

\footnotetext{
${ }_{3} \mathrm{O}$ autor residiu em Santa Maria/RS por 16 anos, onde trabalhou no Departamento de Metodologia de Ensino e no Programa de Pós-graduação em Educação da UFSM, e publicou artigos na imprensa diária da cidade.

${ }^{4}$ Está lotado atualmente no Departamento de Arte Dramática e atua no Programa de Pósgraduação em Artes Cênicas, ambos da UFRGS.
} 
ordenadas as experiências sensoriais passadas. Não se trata de um mundo artístico reconhecido somente através da relação de fatos. O teatro, como arte efêmera, que só se realiza ao vivo na ação dramática, se reinventa a cada instante. Não é um conhecimento estático, onde podem ser formuladas leis permanentes e imutáveis. O conhecimento no teatro se coloca como uma manifestação artística condicionada por múltiplos aspectos da vida de homens determinados. Uma das coisas mais difíceis para se distinguir na reconstrução das ações, aquilo que realmente demonstra sua estética, é justamente a verdade. Conseguir uma atuação crível, que convença o público, seja no drama, na tragédia ou na comédia, é o desafi o maior dos intérpretes. Pois não é que no teatro pós-dramático ${ }^{5}$ a verdade surge da vida como ela é, no momento em que a cena é apresentada. O teatro não mais

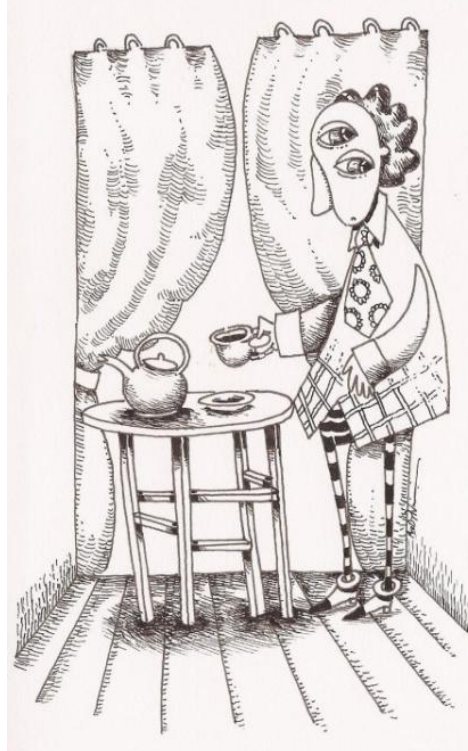
expõe situações, mas presentifica a fábula, como um inventário de acontecimentos particulares. O teatro, portanto, segue uma tendência da pesquisa contemporânea em educação e arte que é investigar trajetórias interessantes de artistas e professores. A construção do personagem é transferida para a ressignificação da vida do próprio ator, que utiliza a palavra, o tom de voz, as intenções, os gestos, as atitudes corporais para comunicar 0 que ele é na verdade. Ou seja, ele busca se reinventar, assim como o teatro de cada dia. Por que os jovens intérpretes e encenadores resolveram expor suas identidades na cena contemporânea?

2. A vontade de atingir o êxito com o trabalho criativo é a busca incessante do artista. Quando uma obra de arte vai a público, a tentativa é de agradar às pessoas. A não ser que o artista não deseje revelar sua criação. Quer queira, quer não, o sucesso junto ao público é objetivo final daqueles que fazem arte.

\footnotetext{
${ }^{5}$ Expressão cunhada por LEHMANN, Hans-Thies. O Teatro Pós-dramático, Cosac Naify,
} 2007. 
Na realidade, a filosofia contemporânea aponta para o destino do ser humano a busca do reconhecimento. Que dirá então o artista? $\mathrm{Na}$ sociedade capitalista, no entanto, esta busca não passa unicamente pela fruição do ato criativo. O consumo da obra de arte está condicionada à forma de distribuição. Com isto, a função de produtor transformou as relações da obra com público. Para a produção artística ser bem sucedida é preciso estar inserida no mercado. Seja nas artes visuais, na música ou nas artes cênicas, quem determina o mercado é a mídia. Para tanto, a atividade de produção tornou-se essencial para penetrar na mídia. O conceito de teatro, baseado na tragédia grega, que, para Aristóteles (1966), era imitação de uma ação completa e interessante, na Idade Média, com os autos, se tornou representação,

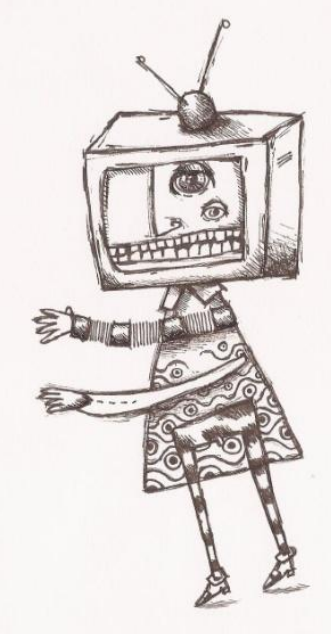
na contemporaneidade é evento, que circula por praças, ruas, picadeiros e, inclusive, nos teatros. Para se tornar evento, é preciso ativar a população e, para isto, devem ser utilizados todos os meios de comunicação, e isto é tarefa da produção. O teatro como mercadoria é aproveitado pela política para lançar seus partidos e personagens. Por vezes, o resultado de tanta pressão comercial inverte o sentido da arte, tranformando o teatro em produto, mais para ser colocado numa gôndola de supermercado do que numa galeria ou num espaço cênico. A quem interessa este jogo?

3. Considerada geralmente como uma arte menor, vide os stand-ups contemporâneos, onde só um ator apresenta seu show, a improvisação é um jogo teatral que resulta na criação de uma cena ou de um espetáculo surgidos de um tema ou de uma imagem. É a maneira mais livre de se fazer teatro. Esta criação poderá ser montada com a distribuição de papéis e falas, ou não, com a ação se desenvolvendo livremente, recebendo estímulos sonoros, visuais e, mais recentemente, da própria plateia que escolhe o que quer assistir na cena. Muitos espetáculos, especialmente na década de setenta, nasceram de improvisações, influenciados que foram pelo Living 
Theatre, grupo norte-americano produtor de verdadeiros happenings cênicos. No Brasil, o trabalho do grupo carioca "Asdrúbal Trouxe o Trombone" se notabilizou através de espetáculos como "Trate-me Leão", baseados em improvisações, nesta forma natural de construir diálogos e situações. O

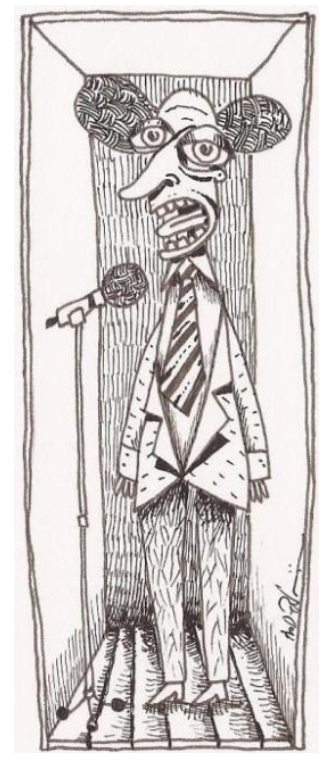

"besteirol", que passou a ser um gênero dramático, foi a forma de driblar a censura e a repressão da época a partir da liberdade pretendida para 0 jogo de palavras $e$ sensações. O humor é consequência inevitável deste valetudo cênico. No Sul, inauguraram este processo de criação cênica os professores Luiz Arthur Nunes e Suzana Saldanha, muito inspirados pelo trabalho da americana Viola Spolin (1979). Juntos, apresentaram "Esta noite arranque a máscara da face e improvise" e "Love, love, love", dois espetáculos criados a partir de improvisações dos atores. "Bailei na Curva", com roteiro e direção de Julio Conte, também partiu das situações criadas pelo grupo para se transformar no espetáculo há mais tempo em cartaz no Rio Grande do Sul. Será que a complexidade da atuação contemporânea, onde o treinamento, a intensidade dos ensaios e as novas tecnologias fazem parte do processo criativo, ainda encontra na improvisação um método para reconstruir situações dramáticas?

4. A luta pelo fim da censura no país atingiu seu ápice em 1978, quando o Serviço Nacional de Teatro premiou com o primeiro lugar o texto de João Ribeiro Chaves Neto, "Patética", no Concurso de Dramatugia. A peça trata, em alegoria, da prisão e morte do jornalista Vladimir Herzog nos porões do DOI-CODI de São Paulo, pelo órgão de repressão. $O$ acontecimento não só deflagrou uma crise entre o Ministério da Educação e o Ministério da Justiça, mas provocou uma mudança de posição da classe artística, que já não mais admitia qualquer censura à sua atividade. $O$ movimento pela livre expressão ganhou força. Em Porto Alegre, a

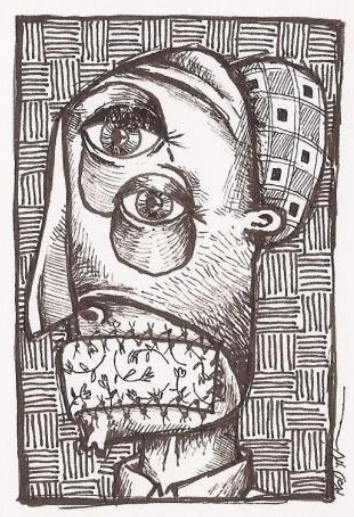


Associação dos Artistas promoveu um ciclo de leituras dramáticas dos textos proibidos, que incluía a peça de João Ribeiro. Mesmo com o Clube de Cultura cercado pela Polícia Federal, a leitura se realizou no teatro completamente lotado. As audiências que se seguiram depois provocaram mais indignação e revolta. Todos os artistas protestavam pelo fim da censura usando tarjas pretas e se manifestavam através de documentos e passeatas. Depois de tanta reivindicação, a Assembleia Nacional Constituinte de 1988 finalmente aprovou o texto que liberou a expressão da atividade artística, científica e de comunicação, assegurando aos criadores, intérpretes e às respectivas representações sindicais o direito de fiscalização sobre 0

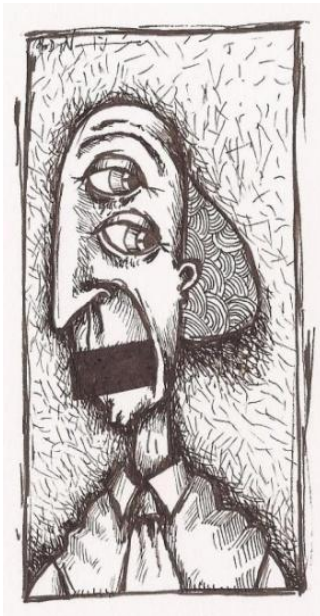
aproveitamento econômico das obras que criarem ou participarem. Terminou, assim, uma das fases mais obscuras da cultura brasileira, que teve consequências terríveis às artes cênicas. Assegurado 0 direito de representar livremente, não se poderá ouvir mais o "está censurado", depois do constragimento de realizar um ensaio geral para a polícia com atores, cenários e figurinos diferentes do espetáculo. Quais seriam as abordagens políticas no teatro contemporâneo?

5. De conformidade com o espírito da arte atual, a ênfase é dada num princípio de ordem mais geral: o tema da obra. A colagem de textos, a fragmentação, a repetição, a perfomance, a vídeoarte, a discotecagem, são características marcantes das encenações contemporâneas. Nada pode ser mais contrário a este princípio do que a cópia. A reprodução pura e simples de sons, imagens e textos tem provocado muita polêmica entre autores e compositores, chegando a ações judiciais. A dramaturgia recriada serve para os propósitos de discussão de uma temática ou apenas para driblar os direitos autorais? Por seus fundamentos, as artes cênicas não possibilitam cópia. Eis que a transitoriedade do tempo, do espaço e das pessoas envolvidas é tão absoluta que se torna inadmissível reviver o mesmo acontecimento mais de uma vez. Sem ser por meios eletrônicos, é impossível ver novamente um espetáculo em idênticas condições. Ao extremo, o que 
vale na cena contemporânea é o hibridismo das linguagens, a perfomance, a inovação das formas. O trabalho de criação na arte contemporânea reúne uma multiplicidade de saberes e fazeres para também multiplicar as percepções do público. O objetivo é atingir cada sujeito da plateia em toda sua subjetividade. Claro, não se pode exigir de jovens estudantes de artes cênicas, estreantes no palco, a genialidade de concepções artísticas absolutamente originais, revolucionárias. A tarefa do ensino de teatro é oportunizar experiências para potencializar a criação cênica. Não é de uma determinada

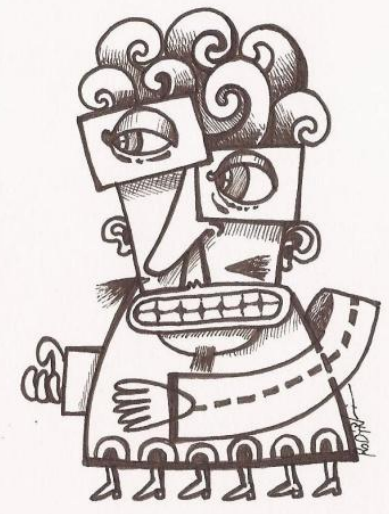
tendência artística predominante que se atinge 0 melhor resultado, porque o teatro está em constante mutação.

6. Múltiplas alternativas de texto estão se tornando possíveis para serem levadas à cena. Os trágicos gregos são muito lembrados, as adaptações de clássicos como Shakespeare, Molière, entre outros. Mas, o autor que tem

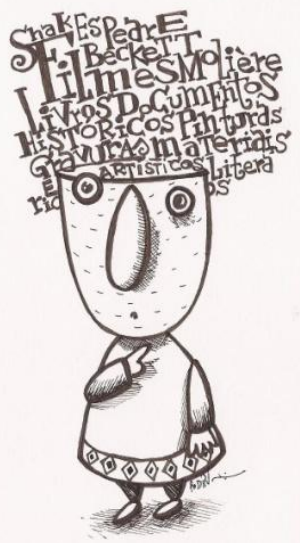
sido encenado com bastante frequência, seja com seus textos integrais ou em adaptações, é Beckett. Num mundo absurdo em que mesmo com toda tecnologia de informação falta comunicação entre as pessoas, somente a experiência beckettiana possibilita uma reflexão com profundidade sobre a existência humana. Sem ser estas práticas dramatúrgicas, o que realmente vai importar para escolha do texto num projeto de montagem é a formação da equipe de trabalho, e, claro, o público que se pretende atingir. A partir destas duas premissas se pode fazer um levantamento dos temas e das propostas cênicas. No entanto, nada será efetivamente desenvolvido sem a pesquisa. Todo contexto artístico e literário envolvido na montagem precisa ser investigado. Filmes, livros, documentos históricos, pinturas, gravuras, esculturas, todo material artístico e literário é bem vindo para transposição de uma idéia para o palco ou para rua. Na medida em que a sociedade passa 
por profundas transformações, escolher o que fazer em cena é extremamente complicado. Em termos de dramaturgia brasileira, então, as contradições são enormes. Autores são constantemente lembrados, como Nelson Rodrigues e Plínio Marcos, e outros mais recentes têm poucas oportunidades de encenação. Foi-se o tempo em que o público assistia a espetáculos unicamente pelos astros e estrelas que faziam parte do elenco. Mesmo que nomes da mídia sejam bons atrativos, não se concebe mais qualquer vaudeville francês ou comédia norte-americana de segunda classe só porque tem alguém muito conhecido no elenco. É a retomada do teatro de ideias e, de preferência, ideias originais. Será que estudantes dos cursos de teatro têm amadurecimento crítico para apresentarem projetos com semelhante estética?

7. Quando a peça, ou o tema, é escolhido com os critérios de responder às necessidades de expressão do grupo e à expectativas da plateia, vem a distribuição dos papéis. O projeto busca satisfazer os desejos de colocar em cena personagens que, de alguma forma, se identificam com atores e atrizes. E aqui não se trata de identificação com aspectos físicos, sociais ou psicológicos, mas com toda uma gama de experiências e sensações que fazem parte da teatralidade. As maiores dificuldades surgem numa direção por encomenda, ou seja, quando o diretor é convidado pelo grupo. Por vezes, os personagens não correspondem aos integrantes do elenco e às

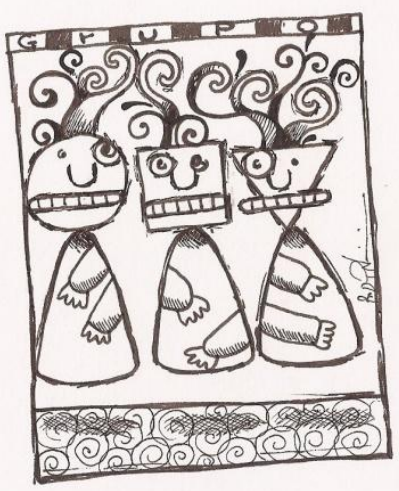
características desses integrantes. Os processos de criação cênica são diferenciados. Ou seja, são os ensaios e a experimentação, enfim, todo treinamento que poderá ajudar nas definições, na integração do texto à interpretação. As montagens da diretora e professora Maria Helena Lopes atestam estas diferenças, ao ponto de, na montagem de um espetáculo, na véspera de estreia, ser suprimido um personagem. Há que se respeitar a proposta estética de encenação. Um segundo ponto a ser abordado é o que se refere à utilização do sistema "coringa", criado pelo teatrólogo Augusto Boal. 
Embora facilitador dos processos de encenação de textos com grande quantidade de personagens, este método pressupõe um trabalho extremamente coeso, para que funcione em cena. Por sua vez, os atores procurarão construir personagens com maior riqueza possível, para revelar diferenças entre eles. Alguns instrumentos, como mapas das cenas, análise descritiva dos objetos e elementos ajudam a superar as dificuldades desta fase da montagem. O desafio permanente para encenadores é compatibilizar os desejos individuais com as necessidades da obra. Até que ponto o processo colaborativo e o trabalho coletivo auxiliam na distribuição de papéis e no resultado esperado pelo público?

8. Não dá para prever o tempo exato para ensaios de um espetáculo. Depende das condições dos integrantes do grupo, dos recursos de produção e da concepção do trabalho. Existem propostas de ensaio como as desenvolvidas pelo Centro de Pesquisas Teatrais, de São Paulo, dirigido por Antunes Filho, que passam mais de ano até serem levadas à cena. Não é o caso da maioria dos grupos que se vêem pressionados por datas previamente agendadas em salas ou pela incapacidade de manutenção da equipe. Nos grupos universitários e de trabalhadores, que possuem uma atividade paralela, é que se encontram as maiores dificuldades. Apesar de pouco tempo de preparação, surpreendem pelos resultados artísticos alcançados, como foi o caso de "O

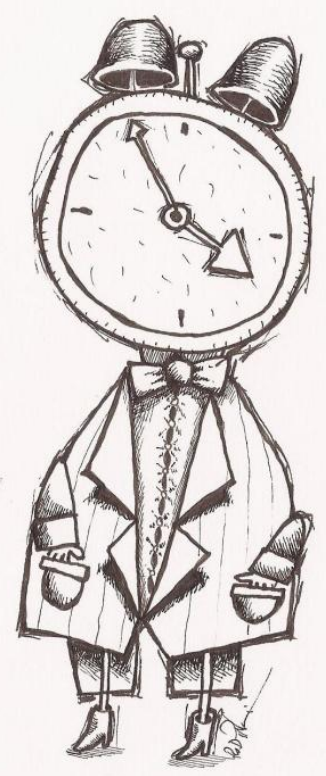
Sobrado", montado pelos alunos do Departamento de Arte Dramática da UFRGS, em 2009, sob a direção da professora Inês Marocco. Tanto no processo longo quanto no mais enxuto, os desafios são enormes e as tarefas complexas diante do processo criativo que envolve a atividade cênica. Do aquecimento inicial, com exercícios e jogos, até a definição dos movimentos cênicos, as discussões são intensas e demandam tempo, fundamental na primeira etapa. Um dos pontos mais complexos do processo de criação é o 
tratamento visual. Cenário, figurinos, acessórios, caracterização dos personagens e iluminação são elementos da linguagem cênica importantes que podem ensejar muitos significados. O parâmetro de competência nesta área é Alziro Azevedo, hoje nome de uma sala de espetáculos do Departamento de Arte Dramática da UFRGS, responsável pela linguagem visual de espetáculos marcantes. Os cenários e figurinos de Alziro foram testemunhos de uma época; ele jamais esquecia de um detalhe, por menor que fosse. O ferro, a madeira, o tecido, todos os materiais tinham objetivo na montagem. Com que cuidado escolhia uma cadeira e colocava no palco! Seu traço partia da cena em movimento, suas observações eram criteriosas. Pesquisava nos briques, frequentava costureiras, viajava para todos lugares possíveis em função do projeto artístico. Como é difícil no teatro contemporâneo encontrar um profissional assim!

9. Sem dúvidas, o trabalho do ator é o fundamento central para todo processo de encenação. Na evolução do espetáculo pode ser visto de diferentes maneiras, mas sempre como ponto de referência para o teatro através dos tempos. Na teoria do dramaturgo alemão Bertolt Brecht (1978), a noção de que o ator assume totalmente um personagem é rejeitada. Dessacralizando o ator, quebrando com a quarta parede, da qual provem a ilusão do palco existir sem público, Brecht propõe nos seus estudos uma nova forma de representar, onde o ator nunca deixa de ser ator. Com o efeito

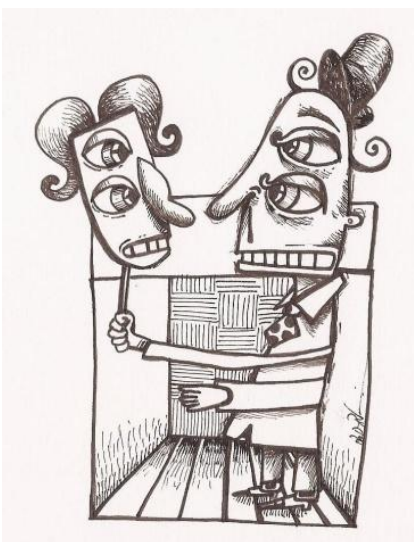
de distanciamento ou estranhamento, a representação, além de empatia, produzirá reflexão crítica. Em cena, 0 ator jamais chega a metamofosear-se inteiramente no personagem. 0 ator não é um Édipo, nem Lear, nem Arpagão, antes, os apresenta. Reconstrói suas falas com a maior autenticidade possível; procura representar sua conduta com tanta perfeição quanto a sua experiência humana permite, mas não tenta persuadir-se (e, desta forma, persuadir a platéia) de que se transformou nos personagens. Brecht assinala que, numa representação em que não se pretende uma metamorfose inteira, 
os atores podem utilizar três formas de recursos para distanciar a expressão e a ação do personagem: 1. recorrência à terceira pessoa (ele); 2. Recorrência ao passado (ele fez); 3. inclusão de indicações e comentários sobre as encenações (por exemplo, ler as rubricas). Se o ator se dirige diretamente ao público, deve fazê-lo francamente e não num mero "à parte", nem tampouco num monólogo. Esta maneira extraordinária de interpretar um personagem e falar sobre ele encontra espaço para treinamento em disciplinas de atuação?

10. Em geral, há uma interpretação equivocada de crítica, no sentido depreciativo do termo. Carrega consigo a ideia negativa de uma expressão, seja artística ou vital. É preciso entender a crítica no seu sentido etimológico, da raiz grega, "kritiké", que quer dizer juízo ou julgamento estético. É Lecoq

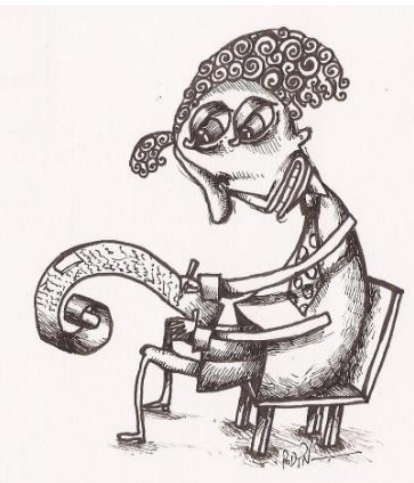
(2010) quem utiliza a expressão "justa" para definir uma ação dramática, que percebeu realizada corretamente. Portanto, não se pode entender crítica como algo destrutivo, ou como uma espécie de exclusão. O exercício da crítica é encarado por este e outros fatores de forma hostil em nossa cultura. Se realmente acreditamos que as artes em geral e o teatro, em particular, podem encarecer imensamente a compreensão que uma sociedade tem de si mesma, podem ajudar a capacidade humana de sentir e refinar suas emoções, que, em resumo, podem contribuir para elevar a qualidade de vida, justifica-se plenamente a existência da crítica. Mas qual seria o papel do crítico numa sociedade do conhecimento. Não é somente contemplar uma obra de arte e, após alguns instantes de reflexão, pronunciar o veredito final "gostei" ou "não gostei”. Há uma longa agonia neste processo, pois ninguém critica aquilo que ele também alguma vez não tenha amado. Significa que produzir crítica requer uma experiência vivida com arte, como fez Adorno (1993), de forma genial. O importante na função de crítico é a tentativa de contribuir para o avanço das artes e da sociedade, divulgando os trabalhos apresentados, oferecendo boas leituras, encorajando artistas, principalmente os mais 
jovens, para que levem seu trabalho adiante. Neste sentido é necessário estar em sintonia com o seu tempo, sem perder os referenciais do passado, na medida em que qualquer valor normativo corre o risco de ser superado pelo insólito dos novos acontecimentos. É preciso acompanhar o trabalho cênico, do projeto à apresentação, passando por todo o processo de criação, como bem fazia o escritor e crítico gaúcho Caio Fernando Abreu. Com os folhetins e as novas tecnologias de informação, a crítica se tornou um território aberto para manifestação de opiniões. São sites, blogs e microblogs que armazenam comentários de todos os tipos, principalmente sobre se o atuante é bom ou ruim, se o diretor foi feliz ou não, como se a arte fosse uma roleta, com apenas dois números. É preciso, através de estudos e observação permanentes de nossa e outras realidades, conseguir uma crítica necessária para descobrirem cada acontecimento artístico aquilo que o torna inovador e questionador, em outras palavras, aquilo que o torna arte.

11. Estes breves textos foram escritos originalmente em 1987, quando recém ingressava no magistério superior, resultados de um período não muito fértil de criação teatral. Talvez o desejo de solucionar imediatamente o impasse arte $x$ educação tenha me levado a publicá-los. Decorridos mais de 20 anos, apresento esta versão no sentido de encontrar novas perguntas para velhos problemas. A preocupação com os fundamentos para o ensino de teatro continua presente, a partir de estudos cênicos comprometidos com as transformações sociais. No entanto, depois de uma dissertação de mestrado e uma tese de doutorado, no meio de

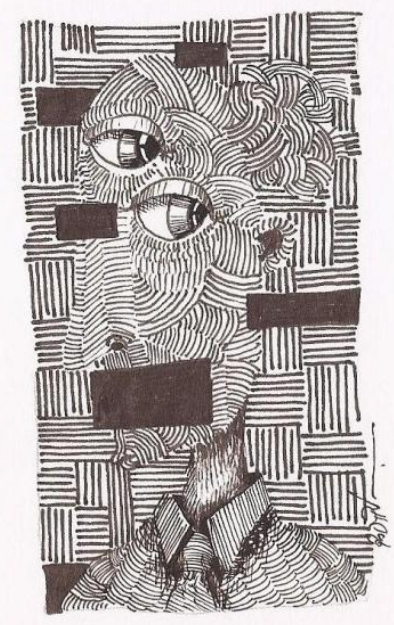
caminhos tortos da prática teatral, proponho estes questionamentos não mais centrados na relação conflituosa que tive desde o início com as artes cênicas, não mais dialetizando o problema com a sociedade, mas com a própria existência humana. Os processos investigativos na educação trouxeram abordagens para a superação e para a sobrevivência não somente individual, mas institucional do teatro, como destacou o professor e pesquisador 
Armindo Bião na palestra promovida pelo Programa de Pós-graduação em Artes Cênicas da UFRGS. E é a este programa que dedico estas "mal traçadas linhas" aqui revistas. As atividades artísticas e docentes permanecem agora Para Além do Jogo ${ }^{6}$, como Dasein, de Heidegger (op. Cit), a indicar experência, presença, síntese do múltiplo e diverso, como o fio de Ariadne, sempre a serviço do pensamento.

\section{REFERÊNCIAS BIBLIOGRÁFICAS}

ADORNO, Theodor W. Teoria Estética. Lisboa: Edições 70, 1993.

ARISTÓTELES. Poética. Porto Alegre: Globo, 1966.

BRECHT, Bertolt. Estudos sobre teatro. Rio de Janeiro: Nova Fronteira, 1978.

HEIDEGGER, Martin. Ser e Tempo. 4 ed. Petrópolis: Vozes, 2009.

LECOQ, Jacques. O Corpo Poético: uma Pedagogia da Criação Teatral. São Paulo: Editora Senac, 2010.

SPOLIN, Viola. Improvisação para o teatro. São Paulo: Perspectiva, 1979.

\footnotetext{
${ }^{6}$ Título da tese de doutorado do autor, UFSM/UNICAMP, 1999.
} 